\title{
Microcephalic osteodysplastic primordial dwarfism types I and III
}

INSERM

\section{Source}

INSERM. (1999). Orphanet: an online rare disease and orphan drug data base. Microcephalic osteodysplastic primordial dwarfism types I and III. ORPHA:2636

Microcephalic osteodysplastic primordial dwarfism (MOPD) types 1 and 3 are characterized by intrauterine and postnatal growth retardation, microcephaly, facial dysmorphism, skeletal dysplasia, low-birth weight and brain anomalies. Although MOPD types 1 and 3 were originally described as two separate entities on the basis of radiological criteria (notably small differences in pelvic and long bone structure), later reports confirmed that the two forms represent different modes of expression of the same syndrome. 